\title{
Studies on Acyl-CoA:Cholesterol Acyltransferase (ACAT) Inhibitory Effects and Enzyme Selectivity of F-1394, a Pantotheic Acid Derivative
}

\author{
Jun Kusunoki, Katsumi Aragane, Tetsuaki Yamaura and Haruo Ohnishi \\ Pharmaceuticals Research Laboratories, Fujirebio Inc., 51 Komiya-cho, Hachioji, Tokyo 192, Japan \\ Received September 8, 1994 Accepted November 29, 1994
}

\begin{abstract}
Dimethylpropyl)-3-nonylureido]aminocyclohexane-1-y] 3-[N-(2,2,5,5tetramethyl-1,3-dioxane-4-carbonyl)amino]propionate (F-1394), a pantotheic acid derivative, is a newly synthesized inhibitor of acyl-CoA:cholesterol acyltransferase (ACAT). In the present study, we investigated the inhibitory effects of F-1394 on the activities of ACAT. F-1394 reduced the ACAT activities in rat liver microsomes, homogenate of rabbit small intestinal mucosa and lysate of $\mathrm{J} 774$ macrophages with $\mathrm{IC}_{50}$ values of $6.4 \mathrm{nM}, 10.7 \mathrm{nM}$ and $32 \mathrm{nM}$, respectively. The kinetic studies showed that F-1394 exerted competitivetype inhibition, and the $K_{i}$ values in liver and small intestinal ACAT were $4.0 \mathrm{nM}$ and $9.9 \mathrm{nM}$, respectively. The inhibitory effects of F-1394 on the activity of ACAT were more potent than that of other ACAT inhibitors or hypolipidemic agents. The study on enzyme selectivity indicated that F-1394 did not affect 3hydroxy-3-methylglutaryl CoA reductase, acyl-CoA synthetase and cholesterol esterase. F-1394 weakly inhibited the activity of lecithine:cholesterol acyltransferase (LCAT) originating from rat plasma. The inhibitory potency of F-1394 for the activity of liver microsomal ACAT was 4,690-fold stronger than that for the activity of LCAT. These findings indicate that F-1394 is a potent and selective inhibitor of ACAT, and its inhibition manner is the competitive type.
\end{abstract}

Keywords: F-1394, Acyl-CoA:cholesterol acyltransferase (ACAT) inhibitor, Pantotheic acid derivative, Competitive inhibition, Enzyme selectivity

Acyl-CoA:cholesterol acyltransferase (ACAT: EC 2.3.1.26) is an enzyme that catalyzes the intracellular esterification of free cholesterol to cholesterol ester, and it appears to be localized to the rough endoplasmic reticulum (1). ACAT has been implicated as a key enzyme involved in absorption of cholesterol via the gut, secretion of very low density lipoprotein (VLDL) from the liver and formation of lipid-filled macrophages and vascular smooth muscle cells (VSMCs), which are closely connected with the progression of atherosclerosis that is the main cause of coronary heart disease (2). Therefore, an ACAT inhibitor may have potential hypolipidemic and antiatherosclerotic activities (3).

The structure-activity relationship study for the moiety of acyl-CoA, a substrate of ACAT, led us to the discovery of a novel ACAT inhibitor, F-1394, $(1 s, 2 s)-2-[3-(2,2-$ dimethylpropyl)-3-nonylureido]aminocyclohexane-1-yl 3[N-(2,2,5,5-tetramethyl-1,3-dioxane-4-carbonyl)amino] propionate (Fig. 1).

The present study was conducted to investigate the inhibitory effect of F-1394 on the ACAT activities originating from rat liver, rabbit small intestinal mucosa and $\mathbf{7 7 4}$ macrophages and compare its effect to those of $N$ - (2, 4 - diffuorophenyl) - $N$ - [[4 - (2, 2 - dimethylpropyl) phenyl]methyl]- $N$-heptylurea $\quad(\mathrm{CL}-277,082) \quad(4), \quad N-(\alpha-$ methylbenzyl)-linoleamide (DL-melinamide, DL-MA) (5), pravastatin, clofibrate and probucol. Furthermore, the effects of F-1394 on the activities of 3-hydroxy-3-methylglutaryl (HMG)-CoA reductase, acyl-CoA synthetase, acid cholesterol esterase (aCEase), neutral CEase (nCEase), pancreatic CEase (pCEase) and lecithine:cholesterol acyltransferase (LCAT) were studied to clarify the enzyme selectivity of F-1394.

\section{MATERIALS AND METHODS}

\section{Drugs}

F-1394, CL-277,082, DL-melinamide and CI-976 (2,2dimethyl- $N$-(2,4,6-trimethoxyphenyl)-dodecanamide) were synthesized by Fujirebio, Inc., Tokyo. Pravastatin sodium and probucol were extracted from Mevalotin ${ }^{\mathbb{Q}}$ (Sankyo Co., Ltd., Tokyo) and Sinlestal ${ }^{\mathfrak{B}}$ (Daiichi 

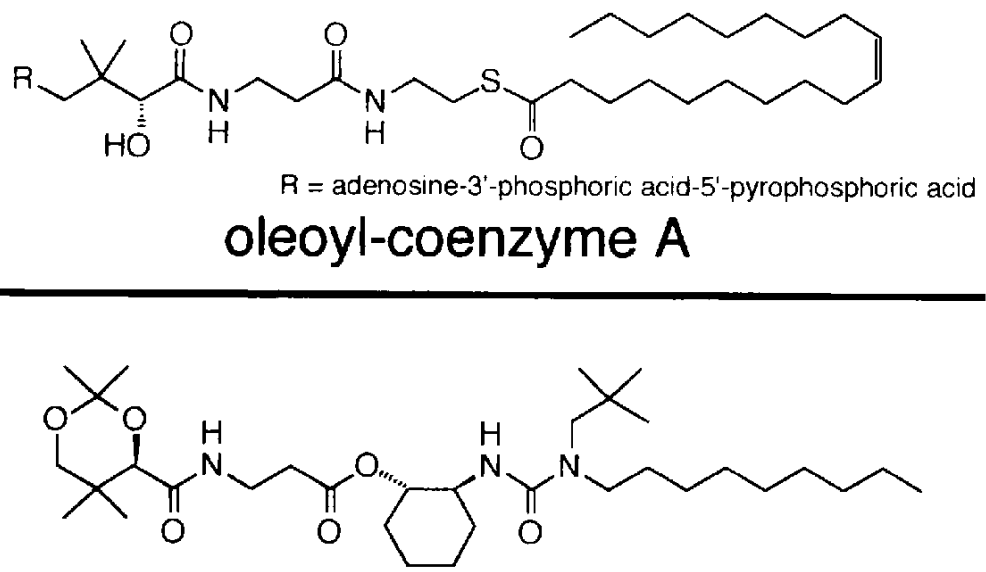

\section{F-1394}<smiles>CCCCCCCCN(Cc1ccc(CC(C)(C)C)cc1)C(=O)Nc1ccc(F)cc1F</smiles><smiles>CCCCC/C=C\C/C=C\CCCCCCCC(=O)NC(C)c1ccccc1</smiles>

\section{DL-melinamide}

Fig. 1. Chemical structures of oleoyl-coenzyme A, F-1394, CL-277,082 and DL-melinamide.

Pharmacetutical Co., Ltd., Tokyo), respectively, in our laboratories. Clofibrate was purchased from Wako Pure Chemical Industries (Osaka).

\section{Other chemicals}

$\left[1{ }^{-14} \mathrm{C}\right]$ Oleoyl-CoA $(2.2 \mathrm{GBq} / \mathrm{nmol}),\left[1{ }^{-14} \mathrm{C}\right]$ cholesteryl oleate $(2.0 \mathrm{GBq} / \mathrm{nmol}), \quad\left[1-{ }^{14} \mathrm{C}\right] \mathrm{palmitic}$ acid $(2.1$ $\mathrm{GBq} / \mathrm{nmol})$, $\left[4-{ }^{14} \mathrm{C}\right]$ cholesterol $(2.1 \mathrm{GBq} / \mathrm{nmol})$ and $[3-$ $\left.{ }^{14} \mathrm{C}\right] \mathrm{HMG}-\mathrm{CoA}(1.8 \mathrm{GBq} / \mathrm{nmol})$ were obtained from New England Nuclear Corp. (Boston, MA, USA). All other chemicals and ware used were standard commercial high purity materials.

\section{Cells and cell culture}

The murine macrophage cell line J774, which was a generous gift from Prof. Y. Saito (Depertment of Laboratory Medicine, School of Medicine, Yamagata University, Yamagata), was grown in a $75-\mathrm{cm}^{2}$ culture flask (Corning, Corning, NY, USA) and maintained in Dulbecco's modified Eagle's medium (DME; Nissui Pharmaceutical Co., Ltd., Tokyo) containing $10 \%$ fetal bovine serum (Gibco, Grand Island, NY, USA) under a humidified atmosphere of $95 \%$ air, $5 \% \mathrm{CO}_{2}$ before use.

\section{ACAT assay}

Livers were removed from male Sprague-Dawley (SD) 
rats (160-180 g; Charles River Japan, Yokohama) fed a commercial chow (F-2; Funabashi Farms, Funabashi) containing $1 \%$ cholesterol, $2.5 \%$ olive oil and $0.2 \%$ cholic acid for 2 weeks and perfused with ice-cold saline. The livers were cut into small pieces and homogenized in $0.154 \mathrm{M}$ potassium phosphate buffer $(\mathrm{pH} 6.2)$. After that, the homogenate was centrifuged at $1,000 \times g$ for $15 \mathrm{~min}$ to discard nuclei and cell debris. The resulting supernatant was centrifuged at $12,000 \times \mathrm{g}$ for $15 \mathrm{~min}$ to remove mitochondria. Then the supernatant was centrifuged at $107,000 \times g$ for $30 \mathrm{~min}$ to obtain microsomes. The sedimented microsomes were suspended in the buffer for use in the experiments.

Small intestines were removed from male Japanese white rabbits (1.8-2.0 kg; Nihon SLC, Hamamatsu) fed a 1\% cholesterol-supplemented rabbit chow (RC-4; Oriental Yeast, Tokyo) for 6 weeks and placed on ice. After being opened longitudinally, the intestinal wall was washed with ice-cold saline. The mucosa was scraped with a microscopic slide and suspended in $0.25 \mathrm{M}$ sucrose solution. The suspension was centrifuged at $900 \times g$ for 10 $\min$. After that, the residue was homogenized in $0.154 \mathrm{M}$ potassium phosphate buffer ( $\mathrm{pH} 6.2)$. The resulting homogenate was centrifuged at $1,000 \times g$ for $15 \mathrm{~min}$, and the resulting supernatant was used for the ACAT assay.

J774 macrophages were cultured for $18 \mathrm{hr}$ in DME containing $1 \%$ of serum, which was obtained from a rabbit fed a $1 \%$-cholesterol diet for a month, in order to load cholesterol in the macrophages. Then the macrophages were homogenized, and the lysate was used for ACAT assay.

ACAT activities in various sources were determined by incorporation of ${ }^{14} \mathrm{C}$-oleoyl-CoA into cholesteryl oleate according to the method of Heider et al. (6). The incubation mixture (total volume of $0.5 \mathrm{ml}$ ) consisting of 0.154 $\mathrm{M}$ of potassium phosphate buffer ( $\mathrm{pH}$ 7.4), $2 \mu \mathrm{M}$ of bovine serum albumin (BSA, Oriental Yeast) and ${ }^{14} \mathrm{C}$ oleoyl-CoA was incubated at $37^{\circ} \mathrm{C}$ for $5 \mathrm{~min}$. After that, ACAT protein and $5 \mu 1$ of dimethylsulfoxide (DMSO; Nacalai Tesque, Kyoto) with the dissolved test compound were added to the mixture, and the incubation was carried out in triplicate assays at $37^{\circ} \mathrm{C}$ for another $5 \mathrm{~min}$. The total lipid fraction in the reaction mixture was extracted according to the method of Folch et al. (7), and cholesteryl oleate in the fraction was isolated by thin layer chromatography (TLC). The radioactivity was detected by a liquid scintillation counter (LSC).

\section{$H M G-C o A$ reductase assay}

Livers were removed at midnight (1:00 a.m.) from male SD rats (160-180 g, Charles River Japan) fed a commercial chow (F-2) containing $2 \%$ cholestylamine for 2 weeks, and the microsomal fraction was prepared as described above. All procedures of this subfractination were carried out in $0.1 \mathrm{M}$ potassium phosphate buffer containing $15 \mathrm{mM}$ of nicotineamide and $2 \mathrm{mM}$ of $\mathrm{MgCl}_{2}$ at $0-4{ }^{\circ} \mathrm{C}$.

HMG-CoA reductase activity in the microsomes was determined by converting ${ }^{14} \mathrm{C}-\mathrm{HMG}-\mathrm{CoA}$ into mevalonolactone according to the method of Kuroda and Endo (8). The $40-\mu l$ incubation mixture consisted of $0.1 \mathrm{M}$ potassium phosphate buffer ( $\mathrm{pH} 7.4$ ), $12.5 \mathrm{mM}$ of ethylenediaminetetraacetic acid (EDTA), $12.5 \mathrm{mM}$ of dithiothreitol, $1.25 \mathrm{mM}$ of $\beta$-nicotineamide adenine dinucleotide phosphate ( $\beta$-NADPH, type I; Sigma, St. Louis, MO, USA) and ${ }^{14} \mathrm{C}-\mathrm{HMG}-\mathrm{CoA}$. The microsomal protein and $2 \mu \mathrm{l}$ of DMSO containing the dissolved test compound were added to the mixture, and the incubation was carried out in triplicate assays for $15 \mathrm{~min}$ at $37^{\circ} \mathrm{C}$. After that, $0.01 \mathrm{ml}$ of $2 \mathrm{M} \mathrm{HCl}$ was added to the mixture, and the incubation was carried out at $37^{\circ} \mathrm{C}$ for another 15 min to convert mevalonic acid to mevalonolactone. The radioactive mevalonolactone was isolated by TLC, and the radioactivity was detected by LSC.

\section{Acyl-CoA synthetase assay}

Small intestines were removed from male SD rats (160-180 g, Charles River Japan) fasted for one night and placed on ice. The intestinal mucosa was scraped with a microscopic slide and suspended in ice-cold $5 \mathrm{mM}$ Tris$\mathrm{HCl}$ buffer containing $0.25 \mathrm{M}$ sucrose. The suspension was centrifuged at $1,000 \times g$ for $10 \mathrm{~min}$ and the resulting supernatant was passed through a nylon mesh. The filtrate was used for the acyl-CoA synthetase assay.

Acyl-CoA synthetase activity in the homogenate was determined by incorporation of ${ }^{14} \mathrm{C}$-palmitic acid into palmitoyl-CoA according to the method of Ber-Tana et al. (9). The incubation mixture (total volume of $0.2 \mathrm{ml}$ ) consisted of $0.15 \mathrm{M}$ of Tris- $\mathrm{HCl}$ buffer (pH 7.2), $20 \mathrm{mM}$ of ATP, $0.2 \mathrm{mM}$ of coenzyme A, $2.25 \mathrm{mM}$ of glutathione, $6.6 \mathrm{mM}$ of $\mathrm{MgCl}_{2}, 0.1 \%$ of triton $\mathrm{X}-100$ and 3.7 $\mathrm{kBq}$ of ${ }^{14} \mathrm{C}$-palmitic acid. Twenty micrograms of the enzyme protein and $2.5 \mu \mathrm{l}$ of DMSO solution containing the dissolved test compound were added to the incubation mixture, and the incubation was performed in triplicate assays for $5 \mathrm{~min}$ at $37^{\circ} \mathrm{C}$. Then $1 \mathrm{ml}$ of Dole's reagent (isopropanol : $n$-heptane : $1 \mathrm{~N} \mathrm{H}_{2} \mathrm{SO}_{4}=40: 10: 1$ ) was added to the mixture to stop the enzyme reaction. One milliliter of $n$-heptane and $0.35 \mathrm{ml}$ of water were added to the mixture. The resulting mixture was shaken vigorously, and the heptane layer was discarded. The radioactivity of ${ }^{14} \mathrm{C}$-palmitoyl-CoA in the aqueous phase was measured by LSC.

\section{CEase assay}

J774 macrophages were sonicated in $10 \mathrm{mM}$ Tris- $\mathrm{HCl}$ 
buffer ( $\mathrm{pH}$ 7.4) containing $0.25 \mathrm{M}$ sucrose, and the lysate was used for the aCEase assay or nCEase assay. Porcine pCEase was purchased from Worthington Biochemical Corp. (Freehold, NJ, USA) and dissolved in the same Tris buffer.

CEase activities in various sources were determined by hydrolysis of cholesteryl- ${ }^{14} \mathrm{C}$-oleate to cholesterol and ${ }^{14} \mathrm{C}$-oleic acid $(10-12)$. The reaction mixture (total volume of $0.2 \mathrm{ml}$ ) consisting of $\mathrm{L}-\alpha$-lysophosphatidylcholine, cholesteryl- ${ }^{14} \mathrm{C}$-oleate, enzyme protein, DMSO containing the dissolved test compound, $0.1 \mathrm{M}$ Tris- $\mathrm{HCl}$ buffer (pH 7.5, nCEase; pH 7.0, pCEase) or $0.1 \mathrm{M}$ acetic buffer (pH 4.5, aCEase) and saline was incubated for $1 \mathrm{hr}$ at $37^{\circ} \mathrm{C}$ (duplicate or triplicate assays). The incubation was stopped by addition of $3.25 \mathrm{ml}$ of Belfrage's solution (methanol : chloroform : $n$-heptane $=1.42: 1.25: 1.00$ ) and $1 \mathrm{ml}$ of $0.1 \mathrm{~N} \mathrm{NaOH}$, and the mixture was shaken vigorously. After that, the mixture was centrifuged, and the radioactivity in the resulting aqueous phase was counted by LSC.

\section{LCAT assay}

Blood was drawn from male SD rats $(160-180 \mathrm{~g}$, Charles River Japan) by using syringes containing $5 \mathrm{mM}$ EDTA solution. The plasma was separated immediately by centrifugation at $4^{\circ} \mathrm{C}$ and used for the LCAT assay.

LCAT activity in the plasma was determined by incorporation of ${ }^{14} \mathrm{C}$-cholesterol into cholesteryl ester according to the method of Bell and Hubert (13). The substrate solution (total volume of $0.6 \mathrm{ml}$ ) containing $0.154 \mathrm{M}$ phosphate buffer ( $\mathrm{pH} 7.4$ ), $1.1 \mathrm{mM}$ 5,5-dithio-bis-2-nitrobenzoic acid (DTNB), 3\% BSA, $7.4 \mathrm{kBq}$ of ${ }^{14} \mathrm{C}$-cholesterol and $0.2 \mathrm{ml}$ of the plasma was incubated for $4 \mathrm{hr}$ at $37^{\circ} \mathrm{C}$. After that, $20 \mu \mathrm{l}$ of the phosphate buffer containing 9.4 $\mathrm{mM} 2$-mercaptoethanol and $5 \mu \mathrm{l}$ of F-1394 dissolved in DMSO were added to the substrate mixture, and the incubation was carried out in triplicate assays at $37^{\circ} \mathrm{C}$ for another $40 \mathrm{~min}$. The isolation and measurement of radioactive esterified cholesterol was performed as described in the ACAT assay.

\section{RESULTS}

\section{Effects on activities of ACATs}

The ACAT activity in rat liver microsome was $129.1 \pm 6.5 \mathrm{pmol} / \mathrm{mg}$ microsome $/ \mathrm{min}$. F-1394, CL-277,082 and DL-MA inhibited the ACAT activity in rat liver (Fig. 2a) in a dose-dependent fashion with the estimated $\mathrm{IC}_{50}$ values of $6.4 \mathrm{nM}, 23 \mathrm{nM}$ and $130 \mathrm{nM}$, respectively (Table 1). The ACAT activity in the homogenate of rabbit small intestinal mucosa was $28.8 \pm 1.4 \mathrm{pmol} / \mathrm{mg}$ protein/min. F-1394, CL-277,082 and DL-MA inhibited the activity in rabbit small intestinal mucosa (Fig. 2b) in a
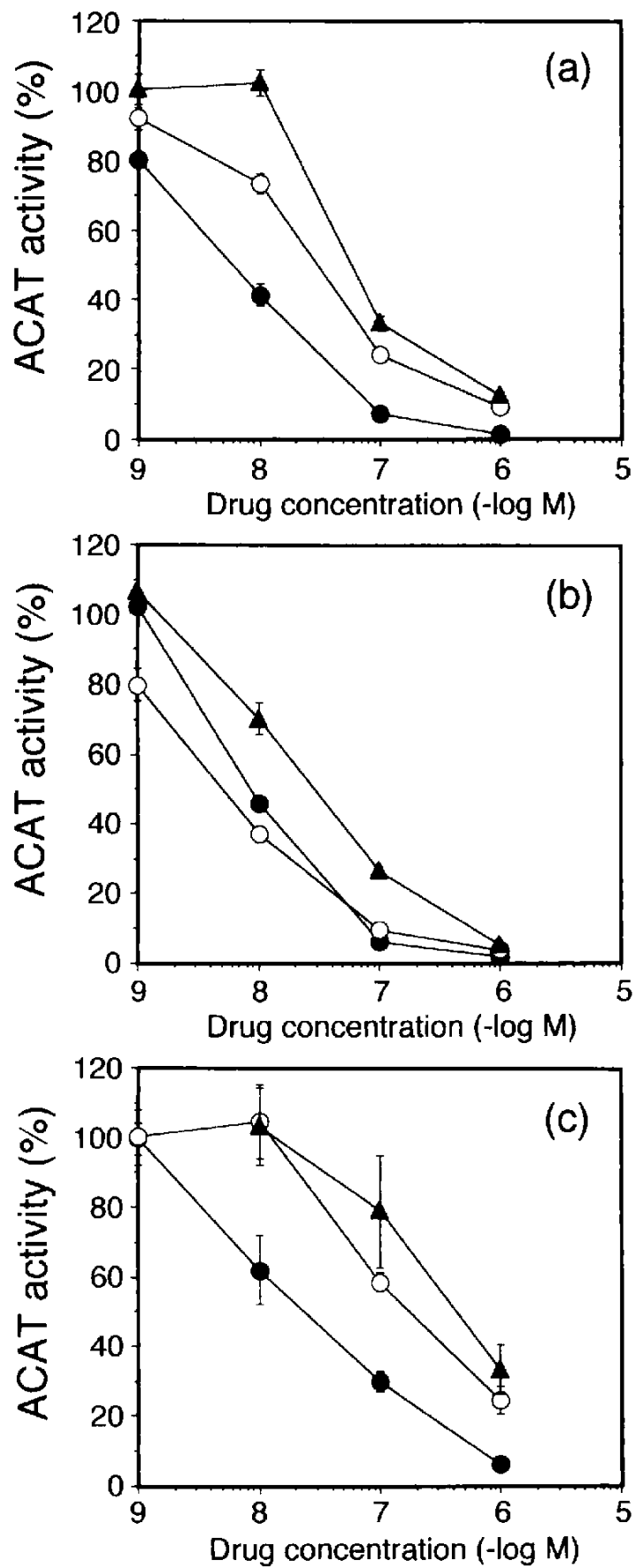

Fig. 2. Effects of F-1394, CL-277,082 and DL-melinamide on the activities of ACAT originating from rat liver microsomes (a), homogenate of rabbit small intestinal mucosa (b) or lysate of J774 macrophages (c). ACAT activity was determined by incorporation of ${ }^{14} \mathrm{C}$-oleoyl-CoA into cholesterol oleate according to the method of Heider et al. (ref. 6) The reaction mixture (total volume of $0.5 \mathrm{ml}$ ) consisted of $0.154 \mathrm{M}$ of potassium phosphate buffer ( $\mathrm{pH} 7.4$ ), $2 \mu \mathrm{M}$ of BSA, ${ }^{14} \mathrm{C}$-oleoyl-CoA, enzyme protein and $5 \mu$ of test compound dissolved in DMSO. The incubation was carried out for 5 min at $37^{\circ} \mathrm{C}$. Lipids in the reaction mixture were extracted by chloroform : methanol (2:1), and the radioactive product was isolated by TLC. The radioactivity was detected by a liquid scintillation counter. Each symbol represents a mean \pm S.E. (duplicate or triplicate assay). : F-1394, O: CL-277,082, A: DL-melinamide. 
Table 1. Inhibitory effects of test compounds on the activity of ACAT in rat liver microsomes

\begin{tabular}{lccc}
\hline Test compounds & $\begin{array}{c}\mathrm{IC}_{50} \text { values } \\
(\mathrm{M})\end{array}$ & $\mathrm{K}_{\mathrm{i}}$ values (M) & Inhibition type \\
\hline F-1394 & $6.4 \times 10^{9}$ & $4.0 \times 10^{-9}$ & Competitive \\
CL-277,082 & $2.3 \times 10^{-8}$ & $5.6 \times 10^{-8}$ & Non-competitive \\
DL-Melinamide & $1.3 \times 10^{-7}$ & - & - \\
Pravastatin & $>1.0 \times 10^{-6}$ & - & - \\
Probucol & $>1.0 \times 10^{-6}$ & - & - \\
Clofibrate & $>1.0 \times 10^{-6}$ & - & - \\
\hline
\end{tabular}

ACAT activity in rat liver microsomes was determined by incorporation of ${ }^{14} \mathrm{C}$-oleoyl-CoA into cholesteryl oleate. Liver microsomes were isolated from SD rats fed a high cholesterol diet for 2 weeks. The reaction mixture (total volume of $0.5 \mathrm{ml}$ ) consisted of $0.154 \mathrm{M}$ of potassium phosphate buffer ( $\mathrm{pH} 7.4$ ), $2 \mu \mathrm{M}$ of BSA, $185 \mathrm{MBq}$ of ${ }^{14} \mathrm{C}$-oleoyl-CoA, $0.2 \mathrm{mg}$ of the microsomal protein and $5 \mu \mathrm{I}$ of test compound dissolved in DMSO. The incubation was carried out in triplicate assays for $5 \mathrm{~min}$ at $37^{\circ} \mathrm{C}$. Lipids in the mixture were extracted by chloroform : methanol (2:1), and the radioactive product was isolated by TLC. The radioactivity was detected by a liquid scintillation counter. - , not tested.

Table 2. Inhibitory effects of test compounds on the activity of ACAT in rabbit small intestinal homogenates

\begin{tabular}{lccc}
\hline Test compounds & $\begin{array}{c}\mathrm{IC}_{50} \text { values } \\
(\mathrm{M})\end{array}$ & $\mathrm{K}_{\mathrm{i}}$ values (M) & Inhibition type \\
\hline F-1394 & $1.1 \times 10^{-8}$ & $9.9 \times 10^{-9}$ & Competitive \\
CL-277,082 & $5.8 \times 10^{-9}$ & $4.3 \times 10^{-8}$ & Non-competitive \\
DL-Melinamide & $3.5 \times 10^{-8}$ & - & - \\
Pravastatin & $>1.0 \times 10^{-6}$ & - & - \\
Probucol & $>1.0 \times 10^{-6}$ & - & - \\
Clofibrate & $>1.0 \times 10^{-6}$ & - & - \\
\hline
\end{tabular}

ACAT activity in the homogenate of small intestinal mucosa was determined by incorporation of ${ }^{14} \mathrm{C}$-oleoyl-CoA into cholesteryl oleate. The homogenate of small intestinal mucosa was isolated from Japanese white rabbits fed a high cholesterol diet for 6 weeks. The reaction mixture (total volume of $0.5 \mathrm{ml}$ ) consisted of $0.154 \mathrm{M}$ of potassium phosphate buffer (pH 7.4), $2 \mu \mathrm{M}$ of BSA, $1.85 \mathrm{MBq}$ of ${ }^{14} \mathrm{C}$-oleoyl-CoA, $0.1 \mathrm{mg}$ of the mucosal protein and $5 \mu \mathrm{l}$ of test compound dissolved in DMSO. The incubation was carried out in triplicate assays for $5 \mathrm{~min}$ at $37^{\circ} \mathrm{C}$. Lipids in the mixture were extracted by chloroform : methanol (2:1), and the radioactive product was isolated by TLC. The radioactivity was detected by a liquid scintillation counter. - not tested.

dose-dependent manner with the estimated $\mathrm{IC}_{50}$ values of $11 \mathrm{nM}, 5.8 \mathrm{nM}$ and $35 \mathrm{nM}$, respectively (Table 2 ). The ACAT activity in the lysate of $\mathrm{J} 774$ macrophages was $97.9 \pm 7.4 \mathrm{pmol} / \mathrm{mg}$ protein $/ \mathrm{min}$. F-1394, CL-277,082 and DL-MA inhibited the activity in $\mathrm{J} 774$ macrophages (Fig. 2c) in a dose-dependent manner with the estimated $\mathrm{IC}_{50}$ values of $32 \mathrm{nM}, 230 \mathrm{nM}$ and $450 \mathrm{nM}$, respectively (Table 3). Lineweaver-Burk plot analysis indicated that
Table 3. Inhibitory effects of test compounds on the activity of ACAT in $\mathbf{J} 774$ macrophage homogenates

\begin{tabular}{lcc}
\hline Test compounds & $\mathrm{IC}_{50}$ values (M) & Inhibition at $10^{-4} \mathrm{M}(\%)$ \\
\hline F-1394 & $3.2 \times 10^{-8}$ & - \\
CL-277,082 & $2.3 \times 10^{-7}$ & - \\
DL-Melinamide & $4.5 \times 10^{7}$ & - \\
Pravastatin & $>1.0 \times 10^{-4}$ & 7.7 \\
Probucol & $>1.0 \times 10^{-4}$ & 15.4 \\
Clofibrate & $>1.0 \times 10^{-5}$ & 86.9 \\
\hline
\end{tabular}

ACAT activity in the lysate of $\mathrm{J} 774$ macrophages was determined by incorporation of ${ }^{14} \mathrm{C}$-oleoyl-CoA into cholesteryl oleate. The cell lysate was prepared from $\mathrm{J} 774$ macrophages that were cultured with Dulbecco's modified Eagle's medium containing $1 \%$ of high-cholesterol serum. The high-cholesterol serum was obtained from a New Zealand white rabbit fed commercial chow containing $0.5 \%$ cholesterol for a month. The reaction mixture (total volume of $0.5 \mathrm{ml}$ ) con-

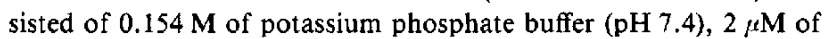
BSA, $2.78 \mathrm{kBq}$ of the substrate, $80 \mu \mathrm{g}$ of cell protein and $5 \mu \mathrm{l}$ test compound dissolved in DMSO. The incubation was carried out in triplicate assays for $5 \mathrm{~min}$ at $37^{\circ} \mathrm{C}$. Lipids in the mixture were extracted by chloroform : methanol $(2: 1)$, and the radioactive product was isolated by TLC. The radioactivity was measured by a liquid scintillation counter. - not tested.

F-1394 was a competitive inhibitor (Fig. 3a), and the $\mathbf{K}_{\mathrm{i}}$ values of F-1394 in the liver and small intestinal mucosa were $4.0 \mathrm{nM}$ and $9.9 \mathrm{nM}$, respectively. In contrast, CL277,082 was a non-competitive inhibitor (Fig. 3b), and the $K_{i}$ values of CL-277,082 in the liver and small intestinal mucosa were $56 \mathrm{nM}$ and $43 \mathrm{nM}$, respectively (Tables 1 and 2). The $\mathrm{IC}_{50}$ values of CI-976 on ACAT activities in rat liver and $\mathrm{J} 774$ macrophages were 2.1- and 1.3-times that of F-1394, respectively. In rabbit small intestine, the $\mathrm{IC}_{50}$ value of CI-976 on ACAT activity was the same as that of F-1394 (data not shown). The inhibition manner of CI-976 was the non-competitive type in rat liver microsomes and rabbit small intestinal mucosa (data not shown).

Pravastatin, probucol and clofibrate had less effect on ACAT activities in the liver, small intestinal mucosa and J774 macrophages, except that $0.1 \mathrm{mM}$ of clofibrate reduced the activity of ACAT in J774 macrophages by 86\% (Tables 1-3).

\section{Effect on activities of other enzymes}

F-1394 at a concentration of $0.1 \mathrm{mM}$ weakly inhibited the activity of HMG-CoA reductase in rat liver microsome by $8.1 \%$. In contrast, $0.1 \mu \mathrm{M}$ of pravastatin, a HMG-CoA reductase inhibitor, inhibited the activity of HMG-CoA reductase by $81.4 \%$ (Table 4).

F-1394 did not affect the activities of acyl-CoA synthetase in rat small intestinal mucosa (Table 5) and acid cholesterol esterase in J774 macrophages (Table 6). 

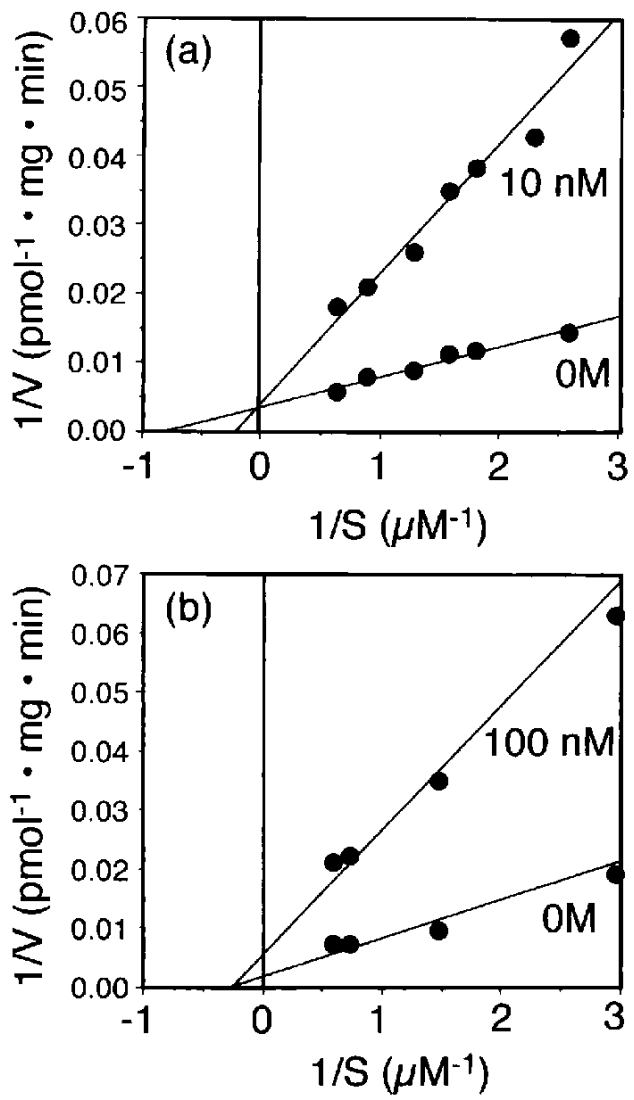

Fig. 3. Lineweaver-Burk plot analysis of the effect of F-1394 (a) and CL-277,082 (b) on the activity of liver microsomal ACAT. ACAT activity in rat liver microsomes was detemined by incorporation of ${ }^{14} \mathrm{C}$-oleoyl-CoA into cholesterol oleate according to the method of Heider et al. (ref. 6) Liver microsomes were isolated from SD rats fed a $1 \%$ cholesterol diet for 2 weeks. The reaction mixture (total volume of $0.5 \mathrm{ml}$ ) consisted of $0.154 \mathrm{M}$ of potassium phosphate buffer ( $\mathrm{pH} 7.4), 2 \mu \mathrm{M}$ BSA, $\left[1-{ }^{14} \mathrm{C}\right]$-oleoyl-CoA $(0.34-1.69 \mu \mathrm{M})$, $0.2 \mathrm{mg}$ of the microsomal protein and test compound dissolved in DMSO. The incubation was caried out for $5 \mathrm{~min}$ at $37^{\circ} \mathrm{C}$. Lipids in the reaction mixture were extracted by chloroform : methanol $(2: 1)$, and the radioactive product was isolated by TLC. The radioactivity was detected by a liquid scintiliation counter. Each symbol represents a mean (triplicate assays).

F-1394 only at a concentration of $10 \mu \mathrm{M}$ inhibited the activity of neutral cholesterol esterase in $\mathrm{J} 774$ macrophages by $27 \%$. On the contrary, F-1394 at a concentration of $0.1 \mathrm{mM}$ enhanced the enzyme activity by $39 \%$ (Table 6). CL-277,082 at a concentration of $0.1 \mathrm{mM}$ reduced the enzyme activity by $35 \%$ (data not shown).

F-1394 had no effect on the activity of porcine pancreatic cholesterol esterase. In contrast, diisopropyl fluorophosphate (DFP), a serine protease inhibitor, at a concentration of $0.1 \mathrm{mM}$ completely inhibited the enzyme activity (Table 6).

The LCAT activity originating from rat plasma was weakly reduced by F-1394 in a dose-dependent manner
Table 4. Effects of F-1394 and pravastatin on the activity of HMG$\mathrm{CoA}$ reductase in rat liver microsomes

\begin{tabular}{|c|c|c|}
\hline Test compounds & $\begin{array}{l}\text { HMG-CoA reductase activity } \\
\text { (nmol/mg microsomes } / \mathrm{min} \text { ) }\end{array}$ & Inhibition $(\%)$ \\
\hline None & $2.10 \pm 0.06$ & 0.0 \\
\hline $\mathrm{F}-1394,10^{-4} \mathrm{M}$ & $1.93 \pm 0.13$ & 8.1 \\
\hline Pravastatin, $10{ }^{7} \mathrm{M}$ & $0.39 \pm 0.02$ & 81.4 \\
\hline
\end{tabular}

HMG-CoA reductase activity was determined by conversion of ${ }^{14} \mathrm{C}$ HMG-CoA into mevalonolactone. Liver microsomes were isolated at midnight from SD rats fed a $2 \%$-cholestylamine diet for 2 weeks. The incubation mixture (total volume of $50 \mu \mathrm{l}$ ) consisted of $0.1 \mathrm{M}$ of potassium phosphate buffer (pH 7.4), $12.5 \mathrm{mM}$ of EDTA, $12.5 \mathrm{mM}$ of dithiothreitol, $1.25 \mathrm{mM}$ of $\beta-\mathrm{NADPH}, 18.5 \mathrm{kBq}$ of the substrate, microsomal protein and $2 \mu \mathrm{l}$ of test compound dissolved in DMSO. The incubation was carried out in triplicate assays for $15 \mathrm{~min}$ at $37^{\circ} \mathrm{C}$. After that, $0.01 \mathrm{ml}$ of $2 \mathrm{M} \mathrm{HCl}$ was added to the mixture, and the incubation was perfomed at $37^{\circ} \mathrm{C}$ for another $15 \mathrm{~min}$ to convert mevalonic acid into mevalonolactone. Mevalonolactone in the reaction mixture was isolated by TLC, and the radioactivity was detected by liquid scintillation counter. The enzyme activities are given as means \pm S.E.

Table 5. Effect of F-1394 on the activity of acyl-CoA synthetase in rat small intestinal homogenates

\begin{tabular}{|c|c|}
\hline Drug concentration & $\begin{array}{l}\text { Acyl-CoA synthetase activity } \\
\text { (nmol } / \mathrm{mg} \text { protein } / \mathrm{min})\end{array}$ \\
\hline None & $2.13 \pm 0.02$ \\
\hline$F-139410^{-6} \mathrm{M}$ & $2.22 \pm 0.14$ \\
\hline $10^{-5} \mathrm{M}$ & $2.21 \pm 0.18$ \\
\hline $10^{-4} \mathrm{M}$ & $2.12 \pm 0.02$ \\
\hline
\end{tabular}

Acyl-CoA synthetase activity in the homogenate of rat small intestinal mucosa was determined by incorporation of ${ }^{14} \mathrm{C}$-palmitic acid into palmitoyl-CoA. The homogenate of small intestinal mucosa was isolated from SD rats fasted for one night. The reaction mixture (total volume of $0.2 \mathrm{ml}$ ) consisted of $0.15 \mathrm{M}$ of $\mathrm{Tris} / \mathrm{HCl}$ buffer (pH 7.2), $20 \mathrm{mM}$ of ATP, $0.2 \mathrm{mM}$ of coenzyme A, $2.25 \mathrm{mM}$ of glutathione, $6.6 \mathrm{mM}$ of $\mathrm{MgCl}_{2}, 0.1 \%$ of triton X-100, $20 \mu \mathrm{g}$ of the mucosal protein, $3.7 \mathrm{kBq}$ of the substrate and $2.5 \mu \mathrm{l}$ of $\mathrm{F}-1394$ dissolved in DMSO. The incubation was carried out in triplicate assays for $5 \mathrm{~min}$ at $37^{\circ} \mathrm{C}$. After that, $1 \mathrm{ml}$ of Dole's reagent (isopropanol : $n$-heptane : $1 \mathrm{~N} \mathrm{H}_{2} \mathrm{SO}_{4}=40: 10: 1$ ), $0.35 \mathrm{ml}$ of water and $1 \mathrm{ml}$ of $n$-heptane were added to the mixture. The radioactivity of the product in the aqueous phase was measured by a liquid scintillation counter. The enzyme activities are given as means \pm S.E.

(Table 7) and the estimated $\mathrm{IC}_{50}$ and $\mathrm{K}_{\mathrm{j}}$ values of $\mathrm{F}-1394$ were $30 \mu \mathrm{M}$ and $64 \mu \mathrm{M}$, respectively.

\section{DISCUSSION}

The present enzymological studies were designed to investigate the ACAT inhibitory potency of F-1394, a pantotheic acid derivative, its manner of inhibition and its enzyme selectivity.

The inhibitory potencies of F-1394 on ACAT activities 
Table 6. Effects of F-1394 on the activities of acid cholesterolesterase (aCEase), neutral cholesterolesterase (nCEase) or pancreatic cholesterolesterase (pCEase)

\begin{tabular}{lcccc}
\hline \multicolumn{2}{l}{ Drug concentration } & $\begin{array}{c}\text { aCEase } \\
\text { (nmol/mg protein } / \mathrm{hr})\end{array}$ & $\begin{array}{c}\text { nCEase } \\
(\mathrm{pmol} / \mathrm{mg} \text { protein } / \mathrm{hr})\end{array}$ & $\begin{array}{c}\text { pCEase } \\
(\mathrm{nmol} / \mathrm{mg} \text { protein } / \mathrm{hr})\end{array}$ \\
\hline None & & $1.87 \pm 0.05$ & $130 \pm 3.9$ & $4.87 \pm 0.13$ \\
$\mathrm{~F}-1394$ & $10{ }^{6} \mathrm{M}$ & $1.79 \pm 0.05$ & $112 \pm 3.0$ & $4.98 \pm 0.15$ \\
& $10^{-5} \mathrm{M}$ & $1.91 \pm 0.15$ & $95 \pm 2.3$ & $5.12 \pm 0.15$ \\
& $10^{-4} \mathrm{M}$ & $1.46 \pm 0.05$ & $181 \pm 8.2$ & $5.46 \pm 0.17$ \\
DFP & $10^{-4} \mathrm{M}$ & - & - & $0.44 \pm 0.18$ \\
\hline
\end{tabular}

Acid cholesterolesterase, neutral cholesterolesterase and pancreatic cholesterolesterase activities were determined by hydrolysis of cholesteryl- ${ }^{14} \mathrm{C}$-oleate to cholesterol and oleic acid. The experimental conditions were described in Materials and Methods. The enzyme activities are given as means \pm S.E. (duplicate or triplicate assays), - , not tested.

Table 7. Effect of F-1394 on the activity of lecithine:cholesterol acyltransferase (LCAT) in rat plasma

\begin{tabular}{|c|c|c|}
\hline Drug concentration & $\begin{array}{c}\text { LCAT activity } \\
(\mathrm{pmol} / \mathrm{ml} \text { plasma } / \mathrm{hr})\end{array}$ & $\begin{array}{c}\text { LCAT activity } \\
(\%)\end{array}$ \\
\hline None & $444.2 \pm 33.5$ & 100.0 \\
\hline $\mathrm{F}-1394 \quad 10^{-7} \mathrm{M}$ & $421.2 \pm 9.7$ & 94.8 \\
\hline $10^{6} \mathrm{M}$ & $378.8 \pm 21.5$ & 85.3 \\
\hline $10^{-5} \mathrm{M}$ & $319.0 \pm 25.2$ & 71.8 \\
\hline $10^{-4} \mathrm{M}$ & $135.8 \pm 3.9$ & 30.6 \\
\hline
\end{tabular}

LCAT activity in rat plasma was determined by incorporation of ${ }^{14} \mathrm{C}$-cholesterol into cholesteryl ester. The substrate solution (total volume of $0.6 \mathrm{ml}$ ) containing $0.154 \mathrm{M}$ of phosphate buffer ( $\mathrm{pH} 7.4$ ), $1.1 \mathrm{mM}$ of DTNB, $3 \%$ of BSA, $0.2 \mathrm{ml}$ of the plasma and $7.4 \mathrm{kBq}$ of ${ }^{14} \mathrm{C}$-cholesterol was incubated for $4 \mathrm{hr}$ at $37^{\circ} \mathrm{C}$. After that, $20 \mu \mathrm{l}$ of phosphate buffer containing $9.4 \mathrm{mM}$ of 2 -mercaptoethanol and $5 \mu 1$ of F-1394 dissolved in DMSO were added to the substrate solution, and the incubation was carried out in triplicate assays at $37^{\circ} \mathrm{C}$ for another $40 \mathrm{~min}$. Lipid in the mixture was extracted by chloroform : methanol (2:1), and the radioactive product was isolated by TLC. The radioactivity was detected by a liquid scintillation counter. The enzyme activities are given as means \pm S.E.

in rat liver, rabbit small intestinal mucosa and $\mathrm{J} 774$ macrophages were, respectively, 20 -fold, 3.2 -fold and 14 -fold stronger than those of DL-MA. Although the inhibitory effect of CL-277,082 on ACAT activity in small intestine was more potent than that of F-1394, the potency of CL277,082 on ACAT activities in rat liver and $\mathrm{J} 774$ macrophages was less than that of F-1394. Furthermore, the affinities of F-1394 to the catalytic site of ACAT in the liver and small intestinal mucosa were 14-fold and 4.3fold greater than those of CL-277,082, respectively (Tables 1-3). When the inhibitory effect of F-1394 on ACAT activities in the liver and $\mathrm{J} 774$ macrophages was compared with that of CI-976, a potent ACAT inhibitor (14), F-1394 was more potent than CI-976. These results suggest that F-1394 is a potent inhibitor of ACAT in enzyme preparations and that the affinity of F-1394 to the catalytic site of ACAT is greatest compared with that of other ACAT inhibitors. Moreover, we indicated that the potencies of ACAT inhibitors on the activities of ACAT varies in different species and tissues. Especially, ACAT activity in the homogenate from rabbit small intestinal mucosa is sensitive to CL-277,082, but not F-1394. However, in a preliminary pulse culture study using ${ }^{14} \mathrm{C}-$ oleic acid as the tracer, the inhibitory potencies of F-1394 on ACAT activities in cultured cells, such as $\mathrm{J} 774$ macrophages and $\mathrm{CaCo}-2$ cells, were strongest compared with other ACAT inhibitors (data not shown).

The kinetic studies showed that F-1394 is a competitive inhibitor, whereas CL-277,082 was a non-competitive inhibitor (Fig. 3). Our results on CL-277,082 agree with the previously report of Largis et al. (15). Natori et al. reported that DL-MA showed un-competitive inhibition on ACAT activity from rabbit small intestinal mucosa (5). Since F-1394 was found as a result of a structure-activity relationship study on the moiety of acyl-CoA, which is a substrate of ACAT, the chemical structure of F-1394, which has pantothenate, is more similar to that of acylCoA as compared with the structures of CL-277,082 and DL-MA (Fig. 1). Therefore, F-1394 may exert competitive inhibition on ACAT activity, unlike CL-277,082 or DL-MA. Field et al. reported that CI-976 was a competitive inhibitor of ACAT in the lysate from $\mathrm{CaCo} 2$ cells (14). However, our result indicates that the inhibition manner of CI-976 is not a competitive type in rat liver and rabbit small intestinal mucosa. Thus, there are two possible explanations for the apparent discrepancy of the data between our group and Field et al.: First, we used isolated tissue preparations from the whole animal for the ACAT assays, while Field and coworkers used the lysate from human intestinal cell line CaCo2; Secondly, the experimental condition in our assay system was different from that used by Field and coworkers, especially with respect to incubation time for the enzyme reaction. Thus, CI-976 (PD128042, fatty acid trimethoxyanilide) (14) has 
no substitute corresponding to pantothenate like DL-MA and CL-277,082 in contrast to F-1394.

In the enzyme selectivity study, F-1394 did not affect HMG-CoA reductase from rat liver (Table 4), acyl-CoA synthetase from rat small intestinal mucosa (Table 5), aCEase from $J 774$ macrophages, nCEase from $J 774$ macrophages and pCEase from swine (Table 6). F-1394 showed weak inhibition on the activity of LCAT originating from rat plasma (Table 7). However, the inhibitory potency of F-1394 against the activity of liver microsomal ACAT activity was 4, 690-fold stronger than that against the activity of LCAT. Moreover, the affinity of F-1394 to the catalytic site of ACAT in rat liver was 16,000 -fold greater than that to the catalytic site of LCAT in rat plasma. Therefore, we conclude that the effect of F-1394 on LCAT activity is negligible. These results suggest that F1394 does not affect a key step of cholesterol biosynthesis in the liver; the enzyme involved in cholesterol absorption via the gut, such as a pCEase (16); and the enzymes implicated in reversed cholesterol transport in the body, such as nCEase (17) and LCAT $(18,19)$; and this drug only affects ACAT. Therefore, our observations indicate that F-1394 does not inhibit the enzymes involved in the utilization of both cholesteryl ester in peripheral cells, such as an aCEase (20), and fatty acid in the body, such as an acyl-CoA synthetase (21).

Non-esterified cholesterol, derived from the diet, is esterified by ACAT in mucosal cells, prior to incorporation into chylomicron particles in the gut, and re-esterification of cholesterol occurs under the influence of hepatic ACAT, prior to incorporation into VLDL particles and release into the circulation (2). Under the atherosclerotic condition including lipoprotein alteration, ACAT catalyzes the growth of lipid droplets in macrophages, and subseqently contributes much to the formation of foam cells that exist in atheroma (20). Thereby, ACAT inhibition may have potential for hypocholesterolemic activity by the prevention of absorption of cholesterol via the gut and secretion of VLDL from the liver, and it may have anti-atherosclerotic activity by impeding the formation of foam cells (3). Indeed, several investigators reported that ACAT inhibition increased the reduction of dietary-cholesterol absorption via the gut in vitro (14) and in vivo (6, 15 ), prevented the release into the circulation of VLDLcholesterol from the liver in vitro (22) and in vivo (23) and inhibited foam cell formation (24).

In this study, we indicated that F-1394 strongly inhibited the activities of ACAT originating from the liver, small intestine and macrophages. Thus, F-1394, a potent ACAT inhibitor, may have therapeutic potential for the treatment of hypercholesterolemia and atherosclerosis. Our results indicated that the inhibitory potency of DLMA on ACAT activities from various sources was much less than that of F-1394 (Tables 1-3). These results suggest that F-1394 may have beneficial anti-hyperlipidemic and anti-atherosclerotic effects in the clinical situation compared with those of DL-MA.

On the other hand, pravastatin, probucol and clofibrate did not inhibit the activities of ACAT in these preparations (Tables $1-3$ ). Therefore, these hypolipidemic agents may not be expected to be drugs for the prevention of cholesterol absorption via the gut and may have no direct effect on atherosclerosis.

In conclusion, F-1394, a pantotheic acid derivative, is a potent and selective inhibitor of ACAT and its inhibition manner is the competitive type.

\section{Acknowledgment}

The authors are grateful to Dr. M. Shibata, Pharmaceuticals Research Laboratories, Fujirebio, Inc., for reading the draft and providing suggestions on language and style.

\section{REFERENCES}

1 Chang T and Doolittle GM: Acylcoenzyme A:cholesterol $O$ acyltransferase. The Enzymes 16, 523-539 (1983)

2 Suckling KE and Stange EF: Role of AcylCoA:cholesterol acyltransferase in cellular cholesterol metabolism. J Lipid Res 26, 647-671 (1985)

3 Sliskovic DR and White AD: Therapeutic potential of ACAT inhibitors as lipid lowering and anti-atherosclerotic agents. Trends Pharmacol Sci 12, 194- 199 (1991)

4 DeVries VG, Schaffer SA, Largis EE, Dutia MD, Wang CH, Bloom JD and Katocs AS Jr.: Potential atherosclerotic agents. 5. An acyl-CoA:cholesterol $O$-acyltransferase inhibitor with hypocholesterolemic activity. Med Chem 29, 1131 - 1133 (1986)

5 Natori K, Okazaki Y, Nakajima T, Hirohashi T and Aono S: Mechanism of inhibition of cholesterol absorption by DLmelinamide: Inhibition of cholesterol esterification. Jpn J Pharmacol 42, 517-523 (1986)

6 Heider JG, Pickens CE and Kelly LA: Role of acyl CoA:cholesterol acyltransferase in cholesterol absorption and its inhibition by $57-118$ in the rabbit. J Lipid Res 24, 1127-1134 (1983)

7 Folch J, Lees $M$ and Sloane SH: A simple method for the isolation and purification of total lipids from animal tissues. $J$ Biol Chem 226, $497-509$ (1957)

8 Kuroda $\mathrm{M}$ and Endo $\mathrm{A}$ : Inhibition of in vitro cholesterol synthesis by fatty acids. Biochim Biophys Acta 486, 70-81 (1977)

9 Ber-Tana J, Rose G and Shapiro B: The purification and properties of microsomal palmitoyl-coenzyme A synthetase. Biochem J 122, 353-362 (1971)

10 Shinomiya M, Matsuoka N, Shirai K, Saito $Y$ and Kumagai A: Studies on cholesterol esterase in rat arterial wall. Atherosclerosis 33, 343-350 (1979)

11 Hajjar DP, Minick CR and Fowler S: Arterial neutral cholesteryl esterase. J Biol Chem 258, 192-198 (1983)

12 Lang LS: Nonoxidative ethanol metabolism: formation of fatty acid ethylesters by cholesterol esterase. Proc Natl Acad Sci USA 79, 3954-3957 (1982)

13 Bell PF and Hubert VE: Inhibition of LCAT in plasma from men and experimental animals by chlorpromazine. Lipids $\mathbf{1 6}$, 
$815-819$ (1981)

14 Field FJ, Albright E and Mathur S: Inhibition of acylcoenzyme A:cholesterol acyltransferase activity by PD128042: Effect on cholesterol metabolism and secretion in CaCo-2 cells. Lipids 26 , 1-8 (1991)

15 Largis EE, Wang $\mathrm{CH}$, DeVries $\mathrm{VG}$ and Schaffer SA: $\mathrm{CL}$ 277,082: a novel inhibitor of ACAT-catalyzed cholesterol esterification and cholesterol absorption. J Lipid Res 30, 681-690 (1989)

16 Gallo LL, Clark SB, Myers S and Vahouny GV: Cholesterol absorption in rat intestine: role of cholesterol esterase and acyl coenzyme A:cholesterol acyltransferase. J Lipid Res 25, 604-612 (1984)

17 Schmitz G, Beuck M, Fischer H, Nowicka G and Robeneck H: Regulation of phospholipid biosynthesis during cholesterol influx and high density lipoprotein mediated cholesterol efflux in macrophages. J Lipid Res 31, $1741-1752$ (1990)

18 Lacko $\mathrm{AG}$ and Pritchard $\mathrm{PH}$ : International symposium on reverse cholesterol transport. Report on meeting. J Lipid Res 31, 2295-2299 (1990)

19 Fielding CJ and Fielding PE: Evidence for a lipoprotein carrier in human plasma catalyzing sterol efflux from cultured fibroblasts and its relationship to lecithine:cholesterol acyltrans- ferase. Proc Natl Acad Sci USA 78, 3911-3914 (1981)

20 Brown MS, Ho YK and Goldstein JL: The cholesterol ester cycle in macrophage foam cells. J Biol Chem 255, 9344-9352 (1980)

21 Kornberg A and Pricer WE Jr: Enzymatic synthesis of the coenzyme A derivatives of long chain fatty acids. J Biol Chem 204, $329-343$ (1953)

22 Cianflone KM, Yasruel Z, Rodriguez MA, Vas D and Sniderman AD: Regulation of apoB secretion from Hep G2 cells: evidence for a critical role for choelsteryl ester synthesis in the responce to a fatty acid challenge. J Lipid Res 31 , 2045-2055 (1990)

23 Krause BR, Pape ME, Kieft K, Auerbach B, Bisgaier CL, Homan R and Newton RS: ACAT inhibition decreases LDL cholesterol in rabbits fed a cholesterol-free diet: Marked changes in LDL cholesterol without changes in LDL receptor mRNA abundance. Arterioscler Thromb 14, 598-604 (1994)

24 Schmitz G, Robenek H, Beuck M, Krause R, Schurek K and Niemann $\mathrm{R}: \mathrm{Ca}^{++}$antagonists and ACAT inhibitors promote cholesterol efflux from macrophages by different mechanisms, I: characterization of cellular lipid metabolism. Arteriosclerosis 8 , $46-56$ (1988) 